\title{
Are Gender and Appearance Important? Exploring the Relationship between Recovery Type and Post-recovery Satisfaction
}

\author{
Wen-Chin Tsao ${ }^{1}, \&$ Jing-Yi Jhang ${ }^{2}$ \\ ${ }^{1}$ Professor, Department of Business Administration, National Chin-Yi University of Technology, Taichung, \\ Taiwan, Republic of China \\ ${ }^{2}$ Postgraduate of Department of Business Administration, National Chin-Yi University of Technology, Taichung, \\ Taiwan, Republic of China \\ Correspondence: Wen-Chin Tsao, Professor, Department of Business Administration, National Chin-Yi \\ University of Technology, Taichung, Taiwan, Republic of China.
}

Received: March 18, 2019

Accepted: April 10, 2019

Online Published: April 17, 2019

doi:10.5539/ibr.v12n5p1

URL: https://doi.org/10.5539/ibr.v12n5p1

\begin{abstract}
Since service failure is inevitable in the service industry, how to remedy the failure and maintain customer satisfaction has become an important management issue for enterprises in marketing. This study took gender and physical attractiveness as moderators, hoping to find a mechanism that is more conducive to improving the effectiveness of failure recovery from the perspective of these two variables. In this study, experimental design was used to design a total of 16 experimental scenarios for model verification. The experiment was conducted on a network platform, and a total of 800 valid experimental samples were completed. The study found that for tangible compensation, female service personnel and physical attractiveness are helpful to improve post-recovery satisfaction. In addition, the opposite sex combination of customers and service personnel will produce better remedial effect than the heterosexual combination. Finally, it is also verified that physical attractiveness is an important moderator. The physical attractiveness of the service personnel enables the recovery type and gender combination to have more positive influence on post-recovery satisfaction, thus it plays an important role in failure recovery strategy. Managerial implications for marketing manager of the service industry as well as directions for future research are also discussed.
\end{abstract}

Keywords: eWOM, psychological compensation, tangible compensation, service recovery, physical attractiveness

\section{Introduction}

According to the well-known marketing law of "the cost of attracting new customers is five times as much as maintaining existing customers", it can be seen that reaching customer satisfaction and maintaining long-term customer relationships are one of the most important cost-saving strategies for enterprises (Kotler et al., 2018). Moreover, the quality of service recovery has great influence on consumers' subsequent behavioral intentions, such as repurchase intention and positive electronic word-of-mouth (eWOM), which have widespread impact under social media (Tsao, 2018). Therefore, research issues related to service failure recovery have been the focus of scholars for many years. The food and beverage $(F \& B)$ industry has the characteristic of inseparability, leading to frequent and intensive contact between service providers and customers in the overall service delivery process, which makes service failure nearly unavoidable (Fisk et al., 1993). Due to rising consumer awareness, coupled with the convenient and diversified channels to reflect complaints and vent grievances, if enterprises fail to deal with service failures in a timely and effective manner, they may not only lose customers, it may also cause damage to the corporate image or other areas due to the spread of negative word-of-mouth (WOM) (Smith et al., 1999; Tsao, 2018).

Service recovery has been discussed by a large number of studies in the past, which included various industries, such as banking, restaurants, car repair, travel agencies, aviation and hotels (Maxham III \& Netemeyer, 2002; Grégoire \& Fisher, 2008; Goodwin \& Ross, 1992; Tsao, 2018), most of which are based on the equity theory. Although there are studies discussing service failures in online shopping, there are significant differences in the service flow between online shopping and physical shopping (Wang et al., 2011; Fan et al., 2010; Lin et al., 2011; Kuo \& Wu, 2012). Compared with the above industries, the food and beverage (F\&B) industry has found that 
customers have a higher degree of interaction with service providers in the process of consumption. Furthermore, customers must be present and have higher involvement in the delivery of core services (ordering and delivery of meals), ancillary services (such as parking or booking services), or error handling processes. Therefore, like hotels, restaurants also belong to the high-contact service industry, and for such a high-contact industry, the discussion of the failure recovery mechanism is particularly important (Tefera \& Govender, 2015; Tsao, 2018). However, few past studies have focused on the issue of service recovery in the F\&B industry. Moreover, due to inseparability and high contact, restaurants have a higher probability of service failure than other service industries (Lewis \& McCann, 2004). More importantly, customers, or even other customers, are present at the moment when mistakes occur and are recovered, thus, the effect of handling mistakes will be more critical to the service providers (Lewis \& McCann, 2004; Petzer \& Steyn, 2006). Therefore, this study takes the F\&B industry as the research object.

Several studies have proved that gender is an important variable in the management of the service industry (McColl-Kennedy \& Sparks, 2003). From a biological point of view, because men and women are physically different, their innate social relations are also different, and women are naturally more capable of communication. Furthermore, from a sociological point of view, men and women have formed different role identities due to gender differences, thus, gradually developing various characteristics and values to influence their interest in work, decision-making mode, and behavior intention (Bem, 1981). Thus, consumers/service providers of different genders have different understanding and judgment of customers' complaints, thereby affecting the customer relations and communication skills. Moreover, physical attractiveness is also a very important factor in service industry management. Related studies have pointed out that people often choose those with attractive appearance as interactive objects, as based on aesthetic feeling, more reward expectations, and the stereotype of "beauty is good" (Delamater \& Myers, 2007). Considering that restaurants belong to a high-contact industry, the gender and physical attractiveness of service personnel may affect the recovery effectiveness the process of handling service failures. However, these moderating factors have not been discussed in-depth in past studies.

This study, from the perspective of gender of customer and service personnel and physical attractiveness of service personnel, used the method of experimental design to test various service recovery types, in order to improve the effectiveness of recovery. This study hopes to reveal the strategic position of gender matching and physical attractiveness in the effectiveness of failure recovery, and provide strategic managerial implications for the selection of front-line service personnel and the deployment of table service personnel in the F\&B industry.

\section{Literature Review and Hypotheses}

\subsection{Service Recovery, Recovery Type, and Post-Recovery Satisfaction}

Compared with other service industries, the F\&B industry is unique that its personnel are highly involved in the service process, resulting in a higher probability of service failure than other service industries (Lewis \& McCann, 2004; Petzer \& Steyn, 2006). Since service failures are inevitable in the service industry, a good service recovery mechanism is an important plan for enterprises to mend their ways (Tsao, 2018). Service recovery is the general term for the response and handling process of enterprises to customers' complaints, and is a remedial action taken to compensate customers for material losses or damage due to not meeting customers' expectations. Service recovery includes both psychological and tangible levels, depending on whether it contains financial elements (Keaveney, 1995).

Psychological compensation means that people use politeness, empathy, respect, and concern, admit their mistakes, explain their mistakes, and apologize to customers during the service recovery process (Smith et al., 1999). Davidow (2003) pointed out that psychological compensation is a kind of compensation with emotional benefits, and enterprises often use apologies as a recovery for service failures. According to the resource exchange theory, psychological compensation involves "love", which represents the emotional concern of enterprises for customers, and means that enterprises will feel sorry and have sympathy for customers' distress and dissatisfaction (Liao, 2007). Tangible compensation refers to compensation for the monetary loss or inconvenience to the customer, as caused by the service failure of the enterprise, which is received in the form of financial added value, such as offering coupons, discounts, refunds, product replacement, or re-service as a remedy (Miller et al., 2000).

Customer satisfaction plays a key role in the research of service recovery. Consumers' satisfaction with the remediation of service failures directly affects their views on the enterprise and their intentions for subsequent actions (Holloway et al., 2005; Tsao, 2018). Consumers' perceived satisfaction after firms' compensation for service failures, either tangible or psychological, means so-called secondary satisfaction (Spreng et al., 1995). Tsao (2018) considered post-recovery satisfaction (PRS) to be the secondary satisfaction in her research. This 
study defines PRS as the subjective and emotional judgment of the transaction-specific recovery effort, as provided by the firm after the consumer has received the remedy. PRS not only affects customer trust, commitment, and loyalty, but also affects positive eWOM and recommendation behavior (Goodwin \& Ross, 1992, Tsao, 2018).

Weun et al. (2004) pointed out that customers who prefer to enjoy the service process tend to perceive the scenario as serious when service failures occur. Therefore, using psychological efforts to remedy the service failures when failures occur cannot reduce consumer dissatisfaction; only tangible compensation with financial elements can reduce the dissatisfaction of consumers. Hoffman et al. (1995) also believed that tangible compensation is more conducive to improving customer satisfaction than psychological compensation. Accordingly, this paper presents the following hypothesis:

H1: Tangible compensation significantly improves PRS, as compared with psychological compensation.

\subsection{Gender and Post-Recovery Satisfaction}

Gender is an important factor in the issue of marketing and human resources management (Beetles \& Crane, 2005; Eagly \& Steffen, 1984). Gender distinguishes between men and women according to their physiological characteristics. Men and women are not only different in physiological and reproductive functions, but also different in consumer preferences, behavior, and problem-solving patterns (Hoyer \& MacInnis, 2008). Past studies have interpreted gender roles in job types based on the theory of social roles, meaning that society perceives different roles of value, judgment, and responsibility over different genders. Thus, preference tendencies regarding job types can be differentiated by gender (Eagly \& Steffen, 1984).

The evolution of gender roles is often related to society, economy, and politics. Through the process of social evolution, stereotyped images of the roles and behaviors of men and women are formed. For example, men are endowed with characteristics of self-affirmation, pursuing achievements, independent, brave, decisive, instrumental, and taking initiative. Women, on the other hand, are expected to be obedient, dependent, attentive, sensitive, and compassionate, which are all related to interpersonal interaction and emotional expression (Li \& Chung, 1996). Men thus are more rational, competitive, independent, externally motivated, and willing to take risks; while women tend to be emotional, cooperative, dependent, internally motivated, and risk averse (Hoyer \& MacInnis, 2008; Garcia-Retamero et al., 2011).

As based on the above, women are more likely to cooperate and avoid risks than men do, and are better at interpersonal interaction and emotional expression. Women are also more likely to be forgiven than men for their mistakes. Therefore, this study argues that if service recovery is provided by female service personnel, customers would be better satisfied than when serviced by male personnel. This study proposes the following hypothesis:

H2: Female service personnel are more helpful to improve PRS than male service personnel.

According to the above literature, men have more rational thinking and behavior and more risk-taking personality characteristics than women. Therefore, this study argues that, when the customers who need service recovery are men, they are better able to perceive and understand service failure at a rational level, and thus, will have a more positive and rational perception of service recovery efforts. This paper proposes the following hypothesis.

H3: After service recovery, male customers tend to feel higher PRS than female customers.

\subsection{Physical Attractiveness and PRS}

People often choose those with higher physical attractiveness as the object of interaction, and the reasons are, as follows: (1) from the perspective of beauty alone, people tend to like beautiful things; (2) people have higher expectations of reward when interacting with attractive people; (3) people tend to have stereotypes about physical attractiveness. That is, people believe that "beauty is good" (DeLamater \& Myers, 2007). Hence, physically attractive people are more likely to be associated with other good traits, such as better interpersonal and communication skills, or positive cognition of other social skills (McColl \& Truong, 2013).

Related studies have pointed out that the service industry is a high-contact industry, and customers intuitively believe that attractive service personnel also have better sales skills. When service personnel are in contact with customers, service personnel with better looks are more able to interact with customers and more effectively induce the consumption behavior (Messner et al., 2006). Baker and Churchill (1987) and Petroshius and Crocker (1989) indicated that advertising models with high physical attractiveness can lead to more favorable evaluation of advertisements. Related research also pointed out that, in addition to increasing interaction with customers and 
influencing their purchasing decision-making, sales personnel with good looks can improve customers' perceived satisfaction (Keh et al., 2013).

Therefore, this study argues that service personnel with high physical attractiveness are more likely to make customers feel high interactional justice in the process of interaction when they make a service failure remedy (Tsao, 2018). This paper presents the following hypothesis:

H4: Service personnel with excellent looks are more likely to improve PRS than those with ordinary looks.

\subsection{Moderating Effect of Gender on the Relationship between Recovery Type and PRS}

First, this study discusses the gender of service providers. In the process of socialization, gender affects the type of work, thus, men are expected to be engaged in work with low expression and high instrumental trait; on the other hand, women's jobs often require high expressive and low instrumental qualities (Li \& Chung, 1996; Eagly \& Steffen, 1984). Based on the above gender stereotype for jobs, restaurant service staffs are of high expression and low instrumental quality, and customers expect different roles from male and female service staffs. In addition, relevant literature also points out that women have more emotional characteristics than men, such as compliance, dependence, cooperation, carefulness, sensitivity, and compassion (Li \& Chung, 1996). Therefore, whether they are engaged in physical or psychological compensation, service providers of different genders may affect the remedial effect. Secondly, the gender influence is inferred upon the served customers, specifically, men have more rational thinking and behavior and more risk-taking characteristics than women do. Therefore, male customers are expected to be more rational facing mistakes in the service process than female customers, and are more inclined to accept explanation and compensation. This study concludes that the impact of tangible or substantial compensation on satisfaction through compensation may be moderated by customers' genders.

On the basis of the above, this study believes that the relationship between the type of recovery and PRS may differ according to gender of both service personnel and customers, and thus, argues that the positive influence of tangible compensation, as mentioned in H1 on PRS, is strengthened by female service personnel and male customers. This paper presents the following hypotheses:

H5: In terms of gender, female service personnel have a stronger influence on the phenomenon that tangible compensation has a more significant effect on PRS than psychological compensation.

H6: In terms of gender, male customers have a stronger influence on the phenomenon that tangible compensation can significantly improve PRS than psychological compensation.

\subsection{Relationship between Gender Mix and PRS}

In 1959, a professor at the Munich University in Germany analyzed the sex pheromones of silkworm moths, and found that the phenomenon of "opposite sex attraction" of insects is due to the "sex pheromone". Using the most advanced instruments, studies have proved that human beings also have the function of secreting and accepting opposite sex pheromones. Sex pheromones act on the hypothalamus of the central nervous system and produce an attraction for the opposite sex through the operation of the nervous system and endocrine system (Lin, 2002). In interpersonal relationships, opposite sex contact will produce a special mutual attraction and exciting force, and people can experience unspeakable emotional demands from it, prompting them to produce positive phenomena for activities and learning. Therefore, the phenomenon of "a mix of Jacks and Jills makes a tough job a breeze" has been scientifically verified. Studies have also found that the psychological effect of heterosexual attraction is often more obvious in men (Chen, 2012).

Based on the opposite sex attraction effect, this study argues that the mix of male and female service personnel and customers is expected to affect PRS; the mix of genders is expected to have better remedial effect. This paper presents the following hypothesis:

H7: Female service personnel produce higher PRS than male service personnel when providing service recovery to male customers.

\subsection{Moderating Effect of Physical Attractiveness on PRS}

Physical attractiveness is a type of static attractiveness; the facial appearance, figure, and dress of a person affect the viewer's perceived attraction evaluation of visual objects (Riggio et al., 1991). People infer a person's personality and characteristics from how he or she looks (Berscheid \& Walster, 1974). Related studies have confirmed that people with physical attractiveness tend to receive more positive evaluation than relatively plain-looking people (Miller, 1970). Good looks also have something to do with good personality or positive personality traits. The individual is rewarded for his or her excellent appearance in the process of social interaction, thus, he/she is more likely to be smooth and successful in activities (Chaiken, 1979). Previous 
studies have found that people with attractive appearance are considered to be more capable, gentle in temperament, healthy in mind, and good in social skills (Buunk \& Dijkstra, 2011).

As the F\&B industry is characterized by a high degree of contact with customers, appearance is extremely important for the service personnel. Based on the above discussion, this study argues that the impact of the combination of compensation type and gender on PRS is mediated by the service personnel's appearance. Service personnel with good looks tend to have a stronger impact on the causal relationship between the abovementioned variables in $\mathrm{H} 5$ and $\mathrm{H} 7$. This paper presents the following hypotheses:

H8: Having female service personnel with good looks to provide tangible compensation can produce higher PRS than psychological compensation.

H9: Good looks of service personnel can strengthen the influence of heterosexual combination on PRS.

\section{Methods}

\subsection{Research Design}

Based on the assumption that, if the external force is not manipulated, it is more difficult for the respondent to use the recall method to review a service error, this study referred to Tsao (2018) and adopted the experimental design method, in order to improve the internal research validity, By designing virtual failure scenarios, the subjects were allowed to imagine themselves in a real environment to measure their intuitive response to the remedy of mistakes. Considering that the subjects should feel natural, the experimental location was not in a laboratory, but a familiar place where Internet is accessible, that is, the so-called field experiment (Wu \& Lin, 2001). In addition, as it is difficult to obtain online consumer samples, carry out random sampling, and conduct sample assignments, this study adopted the quasi-experimental design approach, and used a 2 (recovery type: psychological and tangible) $\times 2$ (service personnel's gender: male and female) $\times 2$ (customer's gender: male and female) $\times 2$ (physical attractiveness: excellent and ordinary) between-subject factorial design. Regarding the subjects, this study recruited them publicly on an online community, and used web hyperlinks to present the non-random assignments of 16 experimental scenarios.

\subsection{Development of Stimuli and Experimental Manipulation}

In order to design a virtual scenario of service failure, it is necessary to determine the failure event, the type of recovery, and physical attractiveness before the formal experiment is carried out. Referring to past studies, this study classified the service failures that may occur in restaurants as service delivery failure (5 items), failure to respond to customer requests ( 2 items), and staff's personal behavior (4 items), for a total of 11 failure events in 3 categories (Hoffman et al., 1995). Then, 80 subjects were asked to rank the issues according to the three criteria of encounter, frequency, and severity. After analysis, this study chose "meal defects" (belonging to the category of service delivery failure) as the criterion. Due to the variety of meal defects, 55 subjects were surveyed in the second round, and this study took "food containing foreign matter" as the virtual error event in this study.

Boshoff (1999) found that some companies use apology, assistance, product replacement, refund, and credits as the method of psychological compensation. Smith et al. (1999) and Cheng (2002) suggested that compensations for errors made by enterprises, such as monetary compensation, discounts, gifts, free merchandise, and coupons, constitute a tangible form of compensation. According to the results of previous studies, this study used apology as psychological compensation and free goods (free meal and complimentary dish) as tangible compensation.

This study cooperated with a restaurant and invited eight service personnel to join the study. Four males and four females were given the number of one to eight, respectively. Photographs, including the upper body of the service personnel, were presented. Other conditions (such as clothes and scenes) shown in the photos were the same, except for the different faces. There were 58 subjects invited to participate in the pretest, and they were asked to give a score of 1 to 10 on the looks of the eight service personnel. Those with the highest scores were selected as the representatives of excellent looks in this experiment, while those with the lowest scores were the representatives of ordinary looks. Results showed that No. 2 male service person has the highest score and the No. 3 male has the lowest score; No. 8 female service personnel has the highest score, and No. 7 has the lowest score.

PRS refers to the subjective and emotional judgment of consumers with regard to the transaction-specific recovery efforts of service providers (Tsao, 2018). Regarding the design of the measurement items, this study referred to Maxham and Netemeyer (2002), and proposed the following five questions (1) I am very satisfied with the handling and resolution of the failure; (2) I am glad that the mistake was properly resolved; (3) I am very satisfied with the attitude of the staff towards service recovery; (4) I am very satisfied with the steps taken 
for service recovery; (5) Overall, I am very satisfied with the service recovery method of the restaurant. All items were measured using a seven-point Likert-type scale, ranging from 1 (strongly disagree) to 7 (strongly agree).

\subsection{Participants and Experimental Procedure}

In order to reach the appropriate subjects, this study took consumers who have experienced service failures in restaurants as the research subjects. After deducting the factor of the gender of the subjects (i.e. the genders of the customers), this study designed eight scenarios as web sites hyperlinks and placed them on the community platform for invitation. The invitation was published on Facebook and Line. Intended participants were asked follow the instructions of the invitation content and click on one of the eight hyperlink web sites to guide the subjects into the experimental scenario and start the complete testing process. In order to avoid the bias of non-random assignment to the experimental results, this study randomly changed the layout of the eight hyperlink web sites week by week.

The scenario copy seen by the subjects consisted of two parts. The first part is a description of the failure scenario, which includes an overview of the restaurant and the process of the service failure. The second part is a description of the recovery process, which includes the appearance of the remedial personnel (including different genders and physical attractiveness) and the recovery methods (two types of recovery methods). After the subjects entered the scenario, they were asked to fill out a questionnaire. A total of 879 questionnaires were distributed in this study. One negative question and one identification question were used to screen out invalid questionnaires. Finally, 79 invalid samples were removed, for a total of 800 valid samples.

Among the subjects in this study, 400 (50\%) were male, and 400 (50\%) were female. The majority (287 subjects; $36 \%$ ) was between 21 and 30 years of age; the second largest age group, comprising 256 individuals (32\%), was between 31 and 40 years of age. In terms of occupation, the largest group worked in the service industry (257 subjects, 32\%), and the second largest group were still in school (202 subjects, 25\%). Regarding the average number of meals in the restaurant per month, 6-10 times was selected by 376 subjects, accounting for $47 \%$ of all the subjects, and more than 11 times was selected by 321 subjects, accounting for $40 \%$ of all the subjects.

\section{Analysis and Results}

\subsection{Reliability Check and Hypotheses Testing}

Cronbach's $\alpha$ of PRS was 0.815 , indicating this construct has a high degree of internal consistency (Wortzel, 1979). Analysis of variation (ANOVA) divided the variance within a set of data into multiple portions depending on the possible sources. In other words, each portion can be attributed to a certain reason (factor). The variances of these factors are obtained and tested for statistical significance, which assists researchers in shedding light on the factors that exert significant influence on experiment results. Furthermore, ANOVA can reveal whether the interaction effects among the factors influenced the experiment results (Tsao et al., 2015). Thus, ANOVA is a suitable means of testing the hypotheses in this study.

The hypotheses were tested using $2 \times 2 \times 2 \times 2$ analysis of variance. For $\mathrm{H} 1-\mathrm{H} 4$ testing, it was necessary to rely on the significance test for main effect of factors. As shown in Table 1, the main effect of recovery type revealed a significant difference in PRS $\left(\mathrm{F}=38.856^{* * * *} ; \mathrm{p}<0.001\right)$. Comparison of the mean values indicated that physical compensation can better improve PRS $\left(\right.$ Mean $_{\text {psychological }}=5.298<$ Mean $\left._{\text {tangible }}=5.612 ; \mathrm{t}=-5.645^{* * *}\right)($ see Table 2) . Thus, H1 is supported. The main effect of service personnel's gender revealed a significant difference in PRS (F $\left.=21.747^{* * * *} ; \mathrm{p}<0.001\right)$. After comparison of the mean values, it is found that female service personnel can improve PRS more than male service personnel $\left(\mathrm{Mean}_{\text {male }}=5.334<\mathrm{Mean}_{\text {female }}=5.577 ; \mathrm{t}=-4.334^{* * *}\right)$ (see Table 2). Thus, $\mathrm{H} 2$ is supported. The main effect of customer's gender on PRS was not significant $(F=2.270 ; p>0.1)$; therefore, H3 is not supported. Finally, the main effect of physical attractiveness presented a significant difference in PRS $\left(\mathrm{F}=60.835^{* * *} ; \mathrm{p}<0.001\right)$. After verifying the mean values comparison, it can be seen that service personnel with excellent looks can improve PRS $\left(\right.$ Mean $_{\text {ordinary }}=5.250<$ Mean $\left._{\text {excellent }}=5.660 ; \mathrm{t}=-7.458^{* * * *}\right)$ (see Table 2). Thus, H4 is supported. From the above verification results, it can be seen that different types of compensation methods, in addition to customer's gender, service personnel's gender, and physical attractiveness, will all affect the recovery effect. 
Table 1. Four-way ANOVA test results

\begin{tabular}{|c|c|c|}
\hline \multirow[t]{2}{*}{ Source } & \multicolumn{2}{|c|}{ PRS } \\
\hline & $\mathrm{F}$ & $\mathrm{p}$ \\
\hline Recovery type (A) & 35.856 & $0.000^{* * * * *}$ \\
\hline Service personnel's gender (B) & 21.474 & $0.000^{* * * *}$ \\
\hline Customer's gender $(\mathrm{C})$ & 2.270 & 0.132 \\
\hline Physical attractiveness (D) & 60.835 & $0.000^{* * * *}$ \\
\hline$(\mathrm{A}) \times(\mathrm{B})$ & 2.628 & 0.105 \\
\hline$(\mathrm{A}) \times(\mathrm{C})$ & 5.866 & $0.016^{* *}$ \\
\hline (B) $\times(\mathrm{C})$ & 4.400 & $0.057^{*}$ \\
\hline$(\mathrm{A}) \times(\mathrm{B}) \times(\mathrm{D})$ & 2.946 & $0.086^{*}$ \\
\hline$(\mathrm{A}) \times(\mathrm{C}) \times(\mathrm{D})$ & 0.052 & 0.819 \\
\hline$(\mathrm{B}) \times(\mathrm{C}) \times(\mathrm{D})$ & 8.513 & $0.004^{* * *}$ \\
\hline
\end{tabular}

Note. ${ }^{*} \mathrm{p}<0.1,{ }^{* *} \mathrm{p}<0.05, * * * \mathrm{p}<0.01$

Table 2. The mean PRS of four factors

\begin{tabular}{cccccc}
\hline Dependent variable: PRS & Mean (I) & Mean (J) & $\begin{array}{c}\text { Mean difference } \\
(\mathrm{I}-\mathrm{J})\end{array}$ & $t$-value & $\mathrm{p}$ \\
\hline $\begin{array}{c}\text { Recovery type } \\
(\mathrm{I}=\text { psychological, J = tangible })\end{array}$ & 5.298 & 5.612 & -0.341 & -5.645 & $0.00^{* * *}$ \\
\hline $\begin{array}{c}\text { Service personnel's gender } \\
(\mathrm{I}=\text { male, J = female })\end{array}$ & 5.334 & 5.577 & -0.243 & -4.334 & $0.00^{* * *}$ \\
\hline $\begin{array}{c}\text { Customer's gender } \\
(\mathrm{I}=\text { male, J = female })\end{array}$ & 5.495 & 5.416 & 0.079 & 1.394 & 0.164 \\
\hline $\begin{array}{c}\text { Physical attractiveness } \\
(\mathrm{I}=\text { ordinary, } \mathrm{J}=\text { excellent })\end{array}$ & 5.250 & 5.660 & -0.409 & -7.458 & $0.00^{* * *}$ \\
\hline
\end{tabular}

Note. ${ }^{*} \mathrm{p}<0.1, * * \mathrm{p}<0.05, * * * \mathrm{p}<0.01$

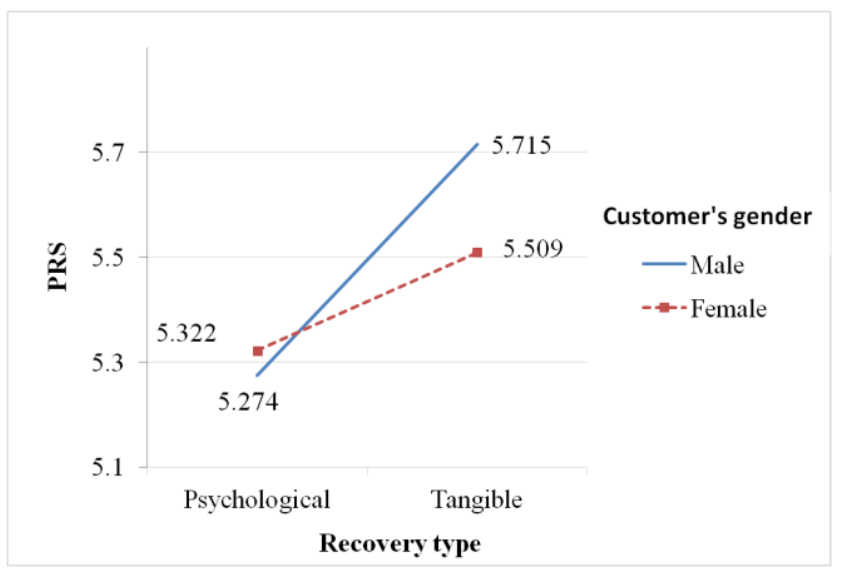

Figure 1. Interaction effect between recovery type and customer's gender on PPS

Next, the interaction between the factors was verified. Table 1 shows that the interaction effect between recovery type and service personnel's gender on PRS was not significant $(F=2.628 ; p>0.1)$; therefore, H5 is not supported. Table 1 also presents that the interaction between recovery type and customer's gender has significant impact on PRS ( $\mathrm{F}=5.866^{* *} ; \mathrm{p}<0.05$ ). It can be seen that the effect of recovery type on PRS will vary depending on the gender of the customer. Then, according to the trumpet shape in Figure 1, it can be seen that the effect of tangible compensation on improving PRS is more significant for male customers than for female customers $\left(\mathrm{Mean}_{\text {tangible, male }}=5.715, \mathrm{Mean}_{\text {tangible, female }}=5.509 ; \mathrm{t}=2.531^{* *}, \mathrm{p}<0.05\right)$. On the contrary, there is no difference in the influence of psychological compensation on PSR due to the gender of customers $\left(\right.$ Mean $_{\text {psychological, male }}=5.274$, Mean $\left._{\text {psychological, female }}=5.322 ; \mathrm{t}=0.638, \mathrm{p}>0.1\right)$. Thus, H6 is supported.

Table 1 shows that the interaction effect between service provider's gender and customer's gender has a 
significant impact on PRS ( $\left.\mathrm{F}=4.400^{*} ; \mathrm{p}<0.1\right)$. It can be seen that service personnel of different genders will affect customers' perceived post-recovery satisfaction with the remedial work. It can be seen from the trumpet shape in Figure 2 that, when service personnel are women, the PRS of male customers is significantly improved than female customers $\left(\right.$ Mean $_{\text {female personal, male customer }}=5.671$, Mean $_{\text {female personnel, female customer }}=5.482 ; \mathrm{t}=2.510^{* *}, \mathrm{p}<$ 0.05). However, the PRS is not affected for male or female customers if service recovery is provided by male service personnel $\left(\right.$ Mean $_{\text {male personal, male customer }}=5.318$, Mean $\left._{\text {male personnel, female customer }}=5.349 ; \mathrm{t}=0.375, \mathrm{p}>0.1\right)$. Therefore, $\mathrm{H} 7$ is supported.

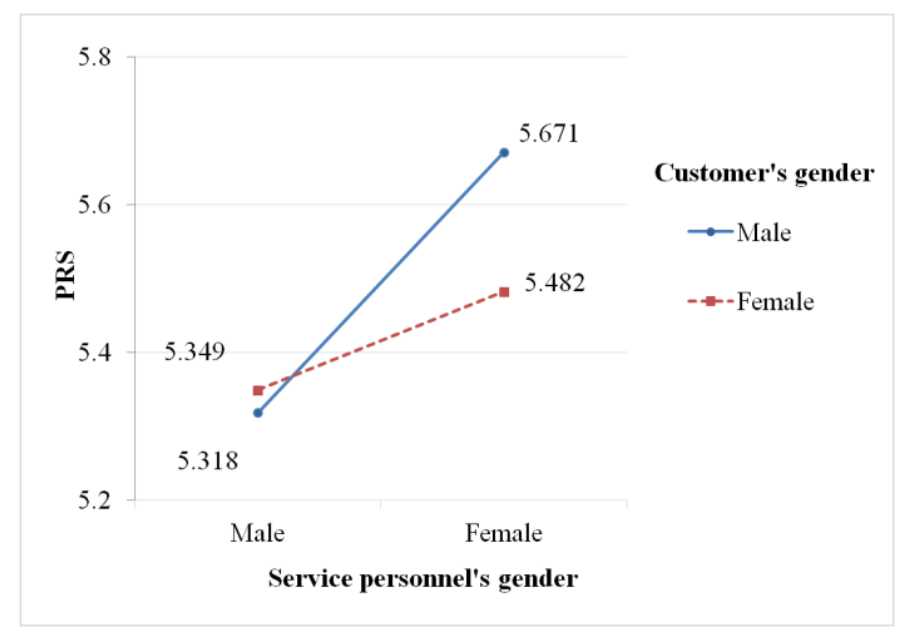

Figure 2. Interaction effect between service personnel's gender and customer's gender on PPS

The abovementioned verification results of H5 found that the interaction between the recovery type and the gender of the service personnel was not significant. However, when considering the physical attractiveness of the service personnel, it was found that the interaction of these three variables was significant $\left(F=2.946^{*} ; \mathrm{p}<0.1\right)$. Therefore, this study continued to use the mean and interaction graph analysis to clarify the interaction among these three variables. Figure 3 (a) shows a trumpet shape, which shows that the interaction between the compensation type and the gender of the service personnel will only occur when the physical attractiveness of the service personnel is ordinary. On the contrary, the two lines in parallel in Figure 3 (b) show that, even if the service personnel are excellent in looks, it will not affect the matching relationship between the compensation method and the gender of the service personnel. This result is contrary to the hypothesis proposed by this study, thus, H8 is not supported.

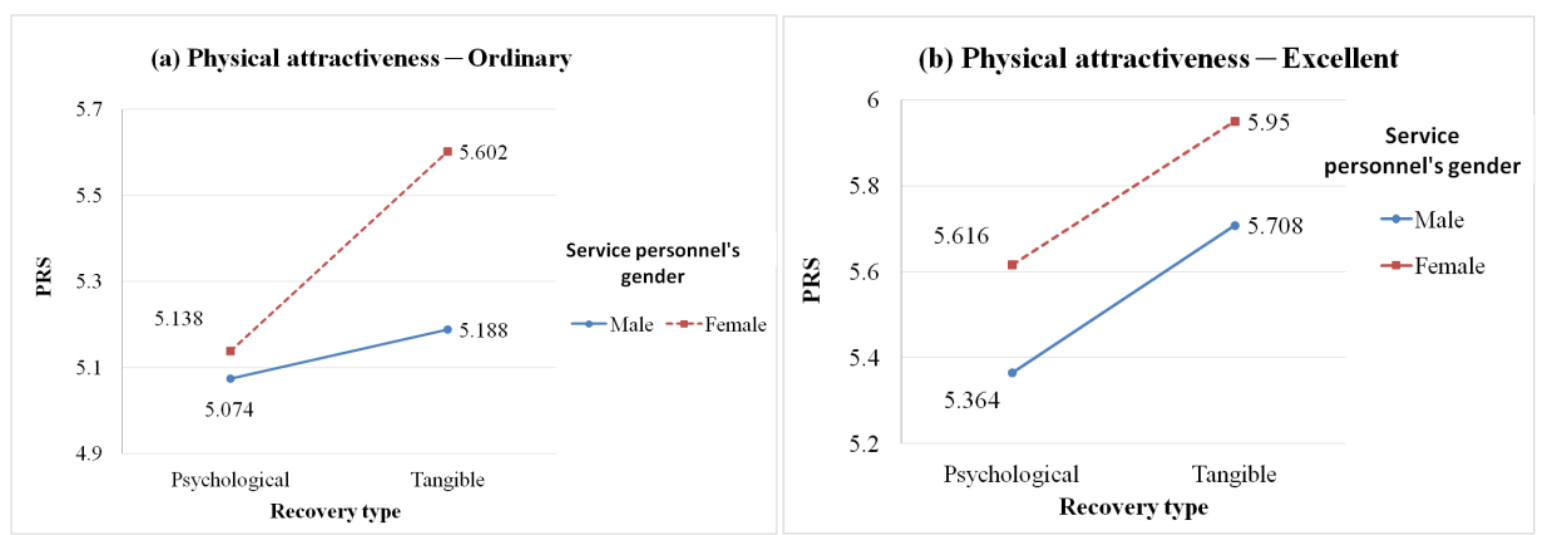

Figure 3. Interaction effect among recovery type, service personnel's gender, and physical attractiveness on PRS

Table 1 shows that the interaction effect among service personnel's gender, customer's gender, and physical attractiveness has significant impact on PRS ( $\left.\mathrm{F}=8.513^{* * *} ; \mathrm{p}<0.01\right)$. Then, the mean and interaction graph analysis were used to further clarify the interaction among variables. As can be seen from the two conditions in 
the two parallel lines in Figure 4 (a), there was no interaction between service personnel's gender and customer's gender when the service personnel's looks were ordinary. That is, when the service personnel's looks were ordinary, the recovery effect of male customers was better regardless of the service personnel's gender. However, according to Figure 4 (b), when the service personnel's looks are excellent, the two lines show a cross shape, indicating significant interaction between the two. From the graphic style and mean value, it can be seen that, when the service personnel's looks are outstanding, the heterosexual combination helps to improve the recovery; especially if the recovery is made by female service personnel, the effect will be more obvious. Thus, H9 is supported.

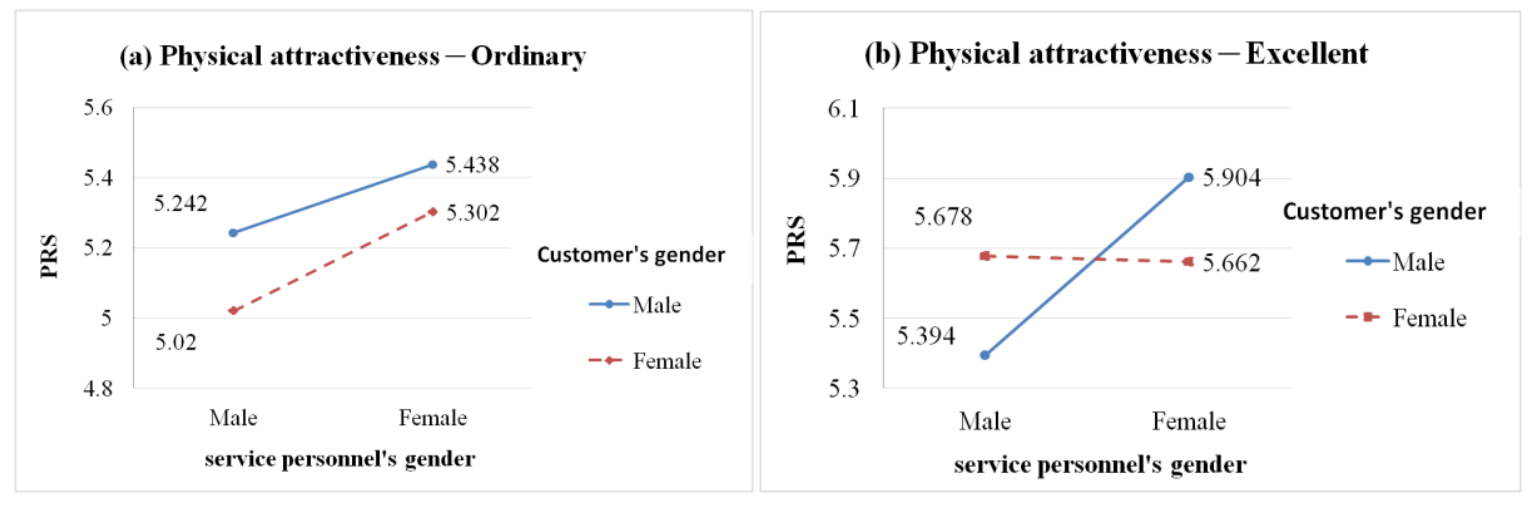

Figure 4. Interaction effect among service personnel's gender, customer's gender, and physical attractiveness on PRS

\section{Discussion and Conclusions}

\subsection{Conclusions}

This study examined the main effect verification of the factors, as shown in Table 1, and found that different types of recovery, service personnel's gender, and physical attractiveness all have different influences on PRS, while customer's gender does not have influence on PRS. Judging from the mean test results between the factors in Table 2, tangible compensation is more effective than psychological compensation, and it is verified that giving customers compensation with financial added value, such as coupons, discounts, refunds, re-production, or re-service, can enhance customer satisfaction. This finding is consistent with previous studies (Miller et al., 2000; Weun et al., 2004). Moreover, regardless of the recovery type and the customer's gender, female service personnel can generate better remedial effect than male service personnel do. Female service personnel who are relatively flexible (submissive, attentive, dependent, compassionate, etc.) and sensitive are preferred by customers, thus, the remedial effect is better than that generated by male service personnel. Furthermore, H4 supported that the looks of the service personnel significantly affect PRS. It is verified once again that, attractiveness of the service personnel has positive impact on the sales performance and model advertising effect, as well as the bonus effect of handling and remedying service failures in the service industry (Baker \& Churchill, 1987; Petroshius \& Crocker, 1989).

According to the verification of recovery type and gender interaction, this study found that customer's gender moderates the influence of recovery type on PRS, while the gender of service personnel does not. As shown in Figure 1, male customers perceive better remedial effect than female customers do when tangible compensation is provided. However, there is no significant difference in the effect between male and female customers when psychological compensation is used. In other words, the positive influence of tangible compensation on PRS is intensified by male customers. Interestingly, the finding on gender matching indicates that the opposite sex combination has different effects on PRS. Figure 2 shows that female service personnel generates more satisfying in service recovery on male customers than on female customers. From the above, it can be seen that the phenomenon of opposite sex attraction can be applied to allocation of service personnel in male-dominated service industries.

This study added physical attractiveness to further deconstruct how this variable affects the interaction between the two abovementioned factors. As can be seen from Figure 3 (a), if service personnel are ordinary in appearance, the impact of tangible compensation on PRS is amplified if the service personnel provide service recovery. On the contrary, if the service providers are attractive appearance, the correlation between the two factors is insignificant (See Figure 3[b]). Thus, tangible compensation provided by female service personnel can 
overcome the offset effect, as caused by the ordinary looks of service personnel, on PRS. However, if the service personnel are attractive, regardless of the compensation method, female service personnel perform better than male service personnel. Although this finding did not support H8 as expected, it does provide an important strategic reference for enterprises that do not have attractive service personnel. Finally, this study also found that the improvement of the recovery effect of the opposite sex combination occurs for employees with attractive looks. Female service personnel with attractive looks can better improve the remedy effect when facing male customers (see Figure 4[b]).

\subsection{Marketing Implications and Contributions}

It is impossible to avoid service failures in the service industry; however, it is important for enterprises to mend their mistakes promptly, and provide satisfying compensation to the consumers, thus enhancing consumers' satisfaction and positive word-of-mouth (Tsao, 2018). According to the results of this study, when other variables are not considered, the three factors of tangible compensation, namely monetary compensation, female service personnel, and attractiveness of the service personnel, have positive effect on the service quality and service recovery if they are properly applied.

Although tangible compensation increases the cost of the enterprise, eWOM is popular in the online community at present, and parsimonious or disappointing compensation would fail to fully compensate the psychological or material losses of consumers, and thus, cause resentment. Once negative word-of-mouth is spread online, it would harm to the company image seriously and extensively (Tsao et al., 2015). If the cost of tangible compensation is regarded as an investment in word-of-mouth management, it could be a cost-effective brand management strategy in the long-term. The above suggestions are especially important for industries targeting male customers.

This study also found that female employees have a key impact on the remedial effect. Overall, female employees are more effective than male employees in handling errors. Moreover, if the gender of customers is considered, female service personnel are more effective in handling service recovery for male customers than for female customers. Therefore, if male customers are the main target customers, the gender allocation of service personnel can be fine-tuned to be female-dominated.

In the past, although there have been studies on the effect of physical attractiveness on post-recovery satisfaction, there have been no discussions on its impact on compensation methods or on gender matching (Keh et al., 2013). This study found that physical attractiveness not only has a significant main effect, but also significant interaction with other variables, which shows that physical attractiveness is an important variable that can be applied in the recovery mechanism. Overall, attractiveness of the service personnel helps improving the recovery effect. When considering the opposite sex pairing between customers and service employees, attractive appearance results in better remedial effect, especially when female employees are matched with male customers. This study incorporated physical attractiveness into the model to examine how to use it to enhance the impact of other variable combinations on PRS, which is a novel and unique contribution of this study. Enterprises can achieve better remedial effect if they can establish a suitable selection mechanism to hire better-looking service personnel, and then, use the opposite sex matching strategy, such as male customers being served by female service personnel, while female customers are being served by male service personnel. The above effect is especially better when it is applied to the dispatch of female employees.

\subsection{Limitations and Directions for Further Research}

Due to the use of experimental design in this study, there are still many possible problems that may affect the results of this study, although rigorous experimental manipulation and data collection were sought in the study process. The limitations of this study are as follows. First, considering the convenience of sampling and the realistic feeling of the experimental environment, the study adopted the quasi-experimental design (Wu \& Lin, 2001). The experimental site is not in a laboratory, thus, the internal effect of the experiment may not be as good as in the laboratory. Second, this study is a non-random sampling of volunteers recruited from an online community. In order to overcome the error of inference, as caused by non-random sampling, the eight experimental scenarios set in this study were randomly changed every week to minimize the error effect of non-random sampling (Tsao, 2018). (3) As this study was conducted online, the population representativeness of the sample may be slightly affected. However, the Internet access rate of Taiwanese people has reached $83 \%$, and age is concentrated on those with high consumption ability (UDN, 2017) under 60 years old, thus, the samples are still representative. Fourth, although four antecedents were included in this research model, other important variables, such as employee rank, failure severity, or restaurant rank, were ignored.

Based on the above research limitations, this study proposed the following suggestions for future studies. First, 
as this study only focused on restaurants, future research can be conducted on service industries of different formats. Second, this study only focused on service recovery type, customer gender, service personnel gender, and physical attractiveness; hence, future research can include other important variables, such as degree of contact, rank of service personnel, restaurant ratings, and failure severity, in order to provide a more complete view and contribute to the service recovery field (Tsao, 2018).

\section{References}

Baker, M. J., \& Churchill, Jr. A. G. (1987). The impact of physically attractive models on advertising evaluations. Journal of Marketing Research, 14(4), 538-555. https://doi.org/10.1177/002224377701400411

Beetles, A., \& Crane, A. (2005). Mapping out the field of gender and buyer-seller relationships: Developing a new perspective. Journal of Marketing Management, 21(1-2), 231-250. https://doi.org/10.1362/0267257053166794

Bem, S. L. (1981). Gender schema theory: A cognitive account of sex typing. Psychological Review, 88(4), 354-364. https://doi.org/10.1037/0033-295X.88.4.354

Berscheid, E., \& Walster, E. (1974). Physical attractiveness. In Advances in experimental social psychology (Vol. 7, pp. 157-215). Academic Press. https://doi.org/10.1016/S0065-2601(08)60037-4

Boshoff, C. (1999). Recovsat: An instrument to measure satisfaction with transaction specific service recovery. Journal of Service Research, 1(3), 236-249. https://doi.org/10.1177/109467059913005

Buunk, A. P., \& Dijkstra, P. (2011). Does attractiveness sell? Women's attitude toward a product as a function of model attractiveness, gender priming, and social comparison orientation. Psychology \& Marketing, 28(9), 958-973. https://doi.org/10.1002/mar.20421

Chaiken, S. (1979). Communicator physical attractiveness and persuasion. Journal of Personality and social Psychology, 37(8), 1387. https://doi.org/10.1037/0022-3514.37.8.1387

Chen, H. (2012). The 108 psychology rules of the lurking office. China: China Overseas Chinese Publishing House.

Cheng, S. C. (2002). The Satisfactory Determinants of Service Recovery Quality: An Exploratory Study. Management Review, 21(3), 49-68. http://dx.doi.org/10.6656/MR.2002.21.3.CHI.49

Davidow, M. (2003). Organizational responses to customer complaints: What works and what doesn't. Journal of Service Research, 5, 225-250. https://doi.org/10.1177/1094670502238917

DeLamater, J. D., \& Myers, D. J. (2007). Social psychology (6th ed.). Belmont, CA: Wadsworth.

Eagly, A. H. \& Steffen, V. J. (1984). Gender stereotypes stem from the distribution of women and men into social roles. Journal or Personality and Social Psychology, 46(4), 735-754. https://doi.org/10.1037/0022-3514.46.4.735

Fan, Y., Wu, C., \& Wu, W. (2010). "The impacts of online retailing service recovery and perceived justice on consumer loyalty”. International Journal of Electronic Business Management, 8(3), 239-249.

Fisk, R. P., Brown, S. W., \& Bitner, M. J. (1993). Tracking the evolution of the service marketing literature. Journal of Retailing, 69(1), 61-103. https://doi.org/10.1016/S0022-4359(05)80004-1

Garcia-Retamero, R., Müller, S. M., \& López-Zafra, E. (2011). The malleability of gender stereotypes: Influence of population size on perceptions of men and women in the past, present, and future. Journal of Social Psychology, 151(5), 635-656. https://doi.org/10.1080/00224545.2010.522616

Goodwin, C., \& Ross, I. (1992). Customer responses to service failures: Influence of procedural and interactional fairness perceptions. Journal of Business Research, 25(2), 149-163. https://doi.org/10.1016/0148-2963(92)90014-3

Grégoire, Y., \& Fisher, R. J. (2008). Customer betrayal and retaliation: when your best customers become your worst enemies. Journal of the Academy of Marketing Science, 36(2), 247-261. https://doi.org/10.1007/s11747-007-0054-0

Hoffman, K. D., Kelley, S. W., \& Rotalsky, H. M. (1995). Tracking service failures and employee recovery efforts. Journal of Service Marketing, 9(2), 49-61. https://doi.org/10.1108/08876049510086017

Holloway, B. B., Wang, S., \& Parish, J. T. (2005), The role of cumulative online purchasing experience in service recovery management. Journal of Interactive Marketing, 19(3), 54-66. https://doi.org/10.1002/dir.20043 
Hoyer, W. D., \& MacInnis, D. J. (2008). Consumer Behavior, Cengage Learning. South-Western, USA.

Keaveney, S. M. (1995). Customer switching behavior in services industries: An exploratory study. Journal of Marketing, 59(2), 71-82. https://doi.org/10.1177/002224299505900206

Keh, H. T., Ren, R., Hill, S. R., \& Li, X. (2013). The beautiful, the cheerful, and the helpful: The effects of service employee attributes on customer satisfaction. Psychology \& Marketing, 30(3), 211-226. https://doi.org/10.1002/mar.20599

Kotler, P., Keller, K. L., Ang, C. T., \& Leong, S. M. (2018). Marketing Management: An Asian Perspective (7 $7^{\text {th }}$ ed.). Person education limited.

Kuo, Y., \& Wu, C. (2012). Satisfaction and post-purchase intentions with service recovery of online shopping websites: Perspectives on perceived justice and emotions. International Journal of Information Management, 32(2), 127-138. https://doi.org/10.1016/j.ijinfomgt.2011.09.001

Lewis, B. R., \& McCann, P. (2004). Service failure and recovery: evidence from the hotel industry. International Journal of Contemporary Hospitality Management, 16(1), 6-17. https://doi.org/10.1108/09596110410516516

Li, M. C., \& Chung, C. Y. (1996). Analysis of gender and gender roles. Indigenous Psychological Research in Chinese Societies, 6, 260-299. http://dx.doi.org/10.6254/1996.6.260

Liao, H. (2007). Do it right this time: the role of employee service recovery performance in customer-perceived justice and customer loyalty after service failures. Journal of Applied Psychology, 92(2), 475-489. https://doi.org/10.1037/0021-9010.92.2.475

Lin, H. H., Wang, Y. S., \& Chang, L. K. (2011). Consumer responses to online retailer's service recovery after a service failure: A perspective of justice theory. Managing Service Quality: An International Journal, 21(5), 511-534. https://doi.org/10.1108/09604521111159807

Lin, J. T. (2002). Human pheromones-The opposite of the opposite sex. Science Education Monthly, 250, 46-56.

Maxham III, J. G., \& Netemeyer, R. G. (2002). A longitudinal study of complaining customers' evaluations of multiple service failures and recovery efforts. Journal of marketing, 66(4), 57-71. https://doi.org/10.1509/jmkg.66.4.57.18512

McColl, R., \& Truong, Y. (2013). The Effects of Facial Attractiveness and Gender on Customer Evaluations during A Web-Video Sales Encounter. Journal of Personal Selling \& Sales Management, 33(1), 117-128. https://doi.org/10.2753/PSS0885-3134330110

McColl-Kennedy, J. R., \& Sparks, B. A. (2003). Application of fairness theory to service failures and service recovery. Journal of service research, 5(3), 251-266. https://doi.org/10.1177/1094670502238918

Messner, M., Reinhard, M., \& Sporer, S. L. (2006). Explicit persuasive intent and its impact on success at persuasion- The determining role of attractiveness and likeableness. Journal of Consumer Psychology, 16(3), 249 - 259. https://doi.org/10.1207/s15327663jcp1603_7|

Miller, J. L., Craighead, C. W., \& Karwan, K. R. (2000). Service recovery: A framework and empirical investigation. Journal of Operations Management, 18(4), 387-400. https://doi.org/10.1016/S0272-6963(00)00032-2

Miller, W. H. (1970). Classical S matrix: Numerical application to inelastic collisions. The Journal of Chemical Physics, 53(9), 3578-3587. https://doi.org/10.1063/1.1674535

Petroshius, S. M., \& Crocker, K. E. (1989). An empirical analysis of spokesperson characteristics on advertisement and product evaluations. Journal of the Academy of Marketing Science, 17(3), 217-225. https://doi.org/10.1177/009207038901700303

Petzer, D. J., \& Steyn, T. F. J. (2006). Customer retention: A theoretical perspective of service failure and service recovery in the hotel industry. Acta Commercii, 6(1), 162-172. https://doi.org/10.4102/ac.v6i1.106

Riggio, R. E., Widaman, K. F., Tucker, J. S., \& Salinas, C. (1991). Beauty is more than skin deep: Components of attractiveness. Basic and Applied Social Psychology, 12(4), 423-439.

https://doi.org/10.1207/s15324834basp1204_4

Smith, A. K., Bolton, R. N., \& Wagner, J. (1999). A model of customer satisfaction with service encounters involving failure and recovery. Journal of Marketing Research, 36(3), 356-372.

https://doi.org/10.1177/002224379903600305 
Spreng, R. A., Harrell, G. D., \& Mackoy, R. D. (1995). Service recovery: impact on satisfaction and intentions. Journal of Services Marketing, 9(1), 15-23. https://doi.org/10.1108/08876049510079853

Tefera, O., \& Govender, K. (2015). Hotel grading, service quality, satisfaction and loyalty-Proposing a theoretical model and relationship. African journal of hospitality, tourism and leisure, 4, 1-17.

Tsao, W. C. (2018). Star power: the effect of star rating on service recovery in the hotel industry. International Journal of Contemporary Hospitality Management, 30(2), 1092-1111. https://doi.org/10.1108/IJCHM-05-2016-0247

Tsao, W. C., Hsieh, M. T., Shih, L. W., \& Lin, T. M. (2015). Compliance with eWOM: The influence of hotel reviews on booking intention from the perspective of consumer conformity. International Journal of Hospitality Management, 46, 99-111. https://doi.org/10.1016/j.ijhm.2015.01.008

UDN (2017). Internet surf rate reach the high record in Taiwan. The network members are about 17.38 million. available at: https://udn.com/news/story/7238/2901859 (accessed 1 March 2019).

Wang, Y. S., Wu, S. C., Lin, H. H., \& Wang, Y. Y. (2011). The relationship of service failure severity, service recovery justice and perceived switching costs with customer loyalty in the context of e-tailing. International Journal of Information Management, 31(4), 350-359. https://doi.org/10.1016/j.ijinfomgt.2010.09.001

Weun, S., Beatty, S. E., \& Jones, M. A. (2004). The impact of service failure severity on service recovery evaluations and post-recovery relationships. Journal of Services Marketing, 18(2), 133-146. https://doi.org/10.1108/08876040410528737

Wortzel, L. (1979). Multivariate analysis. N. J., Prentice Hall.

Wu, W. E., \& Lin, C. H. (2001), Business Research Methods. Wha-Tai publishing, Taipei, Taiwan.

\section{Copyrights}

Copyright for this article is retained by the author(s), with first publication rights granted to the journal.

This is an open-access article distributed under the terms and conditions of the Creative Commons Attribution license (http://creativecommons.org/licenses/by/4.0/). 